\title{
Gross for kids but good for parents: differing messages in advertisements for the same products
}

\author{
Sandra Jones* and Belinda Fabrianesi \\ Centre for Health Initiatives, University of Wollongong, Wollongong, New South Wales 2522, Australia
}

Submitted 18 December 2006: Accepted 4 July 2007: First published online 3 September 2007

\begin{abstract}
Objectives: There has been surprisingly little research into the effects of food advertising on parents' perception of commonly consumed children's food items, although the available research suggests that parents may find nutritional claims in these advertisements confusing. The purpose of the present study was to investigate parents' perceptions of branded snack foods targeted at children, and the extent to which these perceptions are influenced by advertising messages. Design: Using an intercept survey, participants were shown either adult-targeted or child-targeted advertisements for the same food products.

Setting: Central business district of a major Australian city.

Subjects: One hundred adults, mean age 40 years.

Results: The study results suggest that: (1) adults' perceptions of advertised food products and, most importantly, purchase intentions for those products differ according to the version of the advertisement seen (for three of the products, $42-54 \%$ would buy the product after seeing the child version compared with 82-84\% after seeing the adult version); and (2) adults clearly perceive distinctly different messages in advertisements for the same products which are targeting parents vs. those targeting children (e.g. for three of the products, 74-92\% perceived that the adult version of the advertisement suggested the food was nutritionally beneficial compared with $2-14 \%$ perceiving this for the child version).

Conclusions: It is clear that the messages conveyed to children about specific foods are quite different to the messages conveyed to adults - and importantly parents - about the same foods.
\end{abstract}

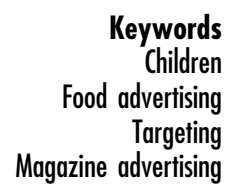

Adequate nutrition during childhood and adolescence is essential for growth and development, health and wellbeing. A child's eating behaviours are established during childhood and may follow them into adulthood ${ }^{1}$.

The growing epidemic of childhood overweight and obesity is a major public health concern in both developed and developing countries ${ }^{2}$. Currently 19-23\% of Australian children and adolescents are overweight or obese $^{3}$, with authorities estimating that about $6 \%$ of Australian children and adolescents are classified as clinically obese ${ }^{4}$. Overweight children are far more likely to become obese as adults 5 .

Research shows that the majority of children consume insufficient amounts of fruit, vegetables, dietary fibre ${ }^{6}$, and milk and meat products; and consume higher than recommended amounts of calorie-dense and high-fat foods $s^{7,8}$.

A variety of factors have been reported to influence food choice, including physiological, psychological ${ }^{9}$, social $^{10}$, environmental ${ }^{11}$ and cultural factors ${ }^{12}$. Television advertising of foods aimed at children has been highlighted as a factor in the increasing levels of childhood obesity, with studies across different countries demonstrating that food advertisements consistently promote high-fat and high-sugar foods ${ }^{13-17}$. However, there is limited evidence of a direct link between food advertisements aimed at children and their eating patterns primarily because, at least for young children, while food preferences may be influenced by child-targeted advertising, food purchase decisions are generally made by parents.

Children's eating behaviours are strongly influenced by the family food environment ${ }^{18}$, including parental food preferences and beliefs, children's food exposure, and parent-child interrelations surrounding food. Media exposure has been discussed above. Parents have both direct and indirect influences over children's food consumption: direct influences include control over food (i.e. what foods are offered $)^{19-21}$ and controls using food (i.e. food-related rewards and punishments ${ }^{22,23}$; indirect 
influences include exposure to different types of foods and to parental food habits and preferences ${ }^{24-26}$.

A UK study of children's food requests revealed that $39 \%$ of the products requested had been advertised within a six-month period leading up to the questionnaire $^{27}$; and a US experimental study reported that pre-school children exposed to food advertising within a videotaped programme were more likely to choose advertised products ${ }^{28}$.

It is important to note that the majority of the current literature focuses on the influence of advertising on children, with little attention paid to parents. However, as discussed above, parents play a central role in children's eating habits as the deciders and purchasers in the family unit $^{29}$. This is particularly the case for younger children, as parents play a major role in educating and providing their children with healthy food choices during the formative years of childhood ${ }^{30}$.

There has been surprisingly little research into the effects of food advertising on parents' perception of commonly consumed children's food items, although the available research suggests that parents may find nutritional claims in these advertisements confusing ${ }^{31}$.

The purpose of the present study was to investigate the extent to which parents' perceptions of branded snack foods targeted at children are influenced by advertising messages. Specifically, we were interested in: (1) whether parents' perceptions of the specific foods and their resultant purchase intentions differed as a result of exposure to child-targeted vs. adult-targeted advertisements for the same products; and (2) whether parents perceived different messages in the child-targeted vs. adult-targeted advertisements.

Magazine advertising was chosen above all other media because it enables greater selectivity of the target audience $^{32}$. By using magazine advertising we were able to identify advertisements for children's food that were clearly targeted at parents and advertisements for the same foods that were clearly targeted at children.

\section{Method}

\section{Stimuli}

Magazine advertisements were monitored by manually examining all issues of the top 30 magazines in Australia based on Audit Bureau of Circulation data from January to June 2004, but limited to magazines that advertised food or beverage products. The stimuli for the study were advertisements for food products targeted at children, taken from current issues of high-circulation Australian magazines. The selection criteria for advertisements were that the same product was advertised in both a children's magazine and an adult magazine during the same month, using a different advertisement. The four advertised products were: Yoplait 'Go-Gurts' (a single-serving yoghurt product); Dairy Whip 'Whipped Cream' (a longlife canned dairy product); Kellogg's 'Coco Pops' (a chocolate-flavoured rice-based breakfast cereal); and Kellogg's 'LCMs' (a rice-based confectionery/snack bar).

\section{Yoplait 'Go-Gurts'}

- Child version: This one-page ad was found in $K$-Zone (February 2005). The ad presents an animated octopus with slime oozing out of its orifices. The ad reads 'Get grossed out with Yoplait Go-Gurts' and contains a series of headlines including 'Totally gross world records: Learn disgusting feats such as how far one man can shoot marshmallows out of his nose' and 'Suck Guts: Totally sick ways to eat yoghurt'.

- Adult version: This one-page ad was found in Australian Good Taste (February 2005), and also appeared in the Australian Family Circle, Super Food Ideas, New Idea and Woman's Day. The advertisement pictures three primary-school children running with the product in their hands, as well as pack shots of the product. The text explains that the product 'contains no fruit lumps or pips ... they'll never know it's full of fruit and good for them' and a sidebar lists 'Calcium for strong teeth and healthy bones; No preservatives and no artificial flavours; Can be frozen or refrigerated for a cool treat; The perfect snack on the go - kids can play while they eat!; Portable and convenient - no mess no fuss; $97 \%$ fat-free'.

\section{Dairy Whip 'Whipped Cream'}

- Child version: This one-page ad was found in $K$-Zone magazine (January 2005), and also appeared in Total Girl. The ad presents photo images of the 'Chocolate La Mousse' and 'Dairy Whip Cream' cans along with pictures of iced chocolate, ice-cream sundae and cakes. The ad reads 'make your dessert more WICKED than ever with DAIRY WHIP!', and presents recipe suggestions on how to use the product whilst encouraging readers to 'use your imagination and create your own awesome recipe!'

- Adult version: This one-page ad was found in New Idea magazine (January 2005). The ad presents a picture of the product being home-delivered along with milk in a crate. The advertisement reads 'Real cream fresh daily'. At the bottom of the advertisement is written 'Made from real farm fresh cream, Dairy Whip is ultra pasteurized to keep fresh longer. Plus it's 20\% lower in fat than regular thickened cream containing 35\% fat. So you can enjoy lashings of it whenever you please. Dairy whip. Real cream. Real easy'.

\section{Kellogg's 'Coco Pops'}

- Child version: This one-page ad was found in Total Girl magazine (May 2005), and also appeared in K-Zone. 
The ad presents the cartoon images of the Coco Pops Gang holding a scroll explaining 'The Legend of Cocotopia' and encourages readers to visit the gang at www.cocopops.com.au. There is also a small picture of the product at the bottom.

- Adult version: This one-page ad was found in New Idea magazine (May 2005), and also appeared in Woman's Day. The advertisement presents a small picture of the product with large text reading 'The only artificial colours are printed on the box'. The ad explains that the product has a balanced mix of eight essential vitamins and minerals including 'B1, B2 and niacin, all of which help release energy in food', 'calcium for strong bones, vitamin $\mathrm{C}$ for healthy teeth and gums, plus iron, zinc and folate, all of which support healthy growth'.

\section{Kellogg's 'LCMs'}

- Child version: This two-page ad was found in $K$-Zone magazine (May 2005), and also appeared in Total Girl. The ad presents cartoon images of four primary-school children, wearing LCM wrappers as clothing, playing a game. The ad presents the rule of a handball game down the left side, and explains the point system down the right side. Four varieties of the products boxes are presented at the bottom, with a spiel encouraging children to visit K-zone's website for 'cool recess challenges, quizzes \& puzzles, as well as online handball!'

- Adult version: This one-page ad was found in Better Homes \& Gardens magazine (May 2005), and also appeared in Super Food Ideas. The ad presents a lunch box containing a salad sandwich, fruit and an LCM bar. It asks the reader to 'THINK OUTSIDE THE BOX'. The text underneath advises the reader that LCMs give energy to refuel children after a morning class; that LCMs are 'made from the goodness of puffed rice' and are 'free from artificial colours'; that 'a variety of foods is recommended by experts to achieve a balanced diet which meets daily nutrition requirements. Adding snacks to the lunchbox helps to increase the variety of a child's diet'; and, lastly, that LCMs are 'just the right size to slip into the lunchbox ... fits into small hands for a no-mess recess ... give kids the energy without spoiling their appetite for the next meal of the day'. Underneath is a picture of two of the varieties of the product.

\section{Participants}

The participants were 100 adults aged between 18 and 74 years (mean: 37.6 years, standard deviation: 12.9 years). Overall, $62 \%$ of the participants were female; $64 \%$ had one or more children; and 55\% had some post-secondary education. Participants were recruited via a shopping centre intercept at a large regional shopping centre in New South Wales (with permission from the shopping centre management).

\section{Metbodology}

Potential participants were approached at an entry to the shopping centre and asked if they would be interested in participating in the study. Those agreeing to participate were randomly allocated to one of two versions of the questionnaire: version one included the four advertisements from the children's magazines, and version two the four advertisements from the adult magazines. Participants viewed each advertisement in turn and were asked three questions about the product and seven questions about the advertisement; at the end of the survey they answered some brief demographic questions.

The questions about the product were: (1) 'Would you purchase this product for yourself?'; (2) 'Would you purchase this product for your children? (Or hypothetically, if you had children, would you purchase this product for them?)'; (3) 'Do you think this product is healthy?' The questions about the advertisements asked participants whether they thought the advertisement's message was that the product was: (1) Nutritionally beneficial; (2) Healthy; (3) Tasty; (4) Fun; (5) Exciting and new; (6) Something that would make one popular; and (7) Convenient. All questions had a 'yes' or 'no' response format.

\section{Results}

There were no statistically significant differences between the two groups in terms of age (mean: 40.0 vs. 35.3 years), gender ( $62 \%$ female in both groups), number of children (average 1.9 children in both groups) or level of education ( $52 \%$ vs. $58 \%$ post-secondary).

\section{Advertisement 1: Yoplait 'Go-Gurt'}

The product

As shown in Table 1, respondents were unlikely to perceive the product as one they would purchase for themselves to consume, regardless of which advertisement they viewed ( $8 \%$ and $6 \%$, respectively). However, their likelihood of purchasing the product for their children varied substantially depending on the version of the advertisement they saw, with $84 \%$ who saw the adult's version stating that they would purchase the product for their child compared with $42 \%$ of those who saw the child's version $\left(\chi^{2}=18.92, P<0.000\right)$. This was also reflected in their perceptions of the product itself; $82 \%$ of those who saw the adult version perceived the product to be healthy while only $38 \%$ of those who saw the child's version had this perception $\left(\chi^{2}=20.17, P<0.000\right)$. 
Table 1 Yoplait 'Go-Gurts'

\begin{tabular}{lcrrr}
\hline & $\begin{array}{c}\text { Adult } \\
\text { version }\end{array}$ & $\begin{array}{c}\text { Child } \\
\text { version }\end{array}$ & \multicolumn{1}{c}{$\chi^{2}$} & $P$ \\
\hline Purchase for self (\%) & 8 & 6 & 0.16 & NS \\
Purchase for child (\%) & 84 & 42 & 18.92 & 0.000 \\
Think it's healthy (\%) & 82 & 38 & 20.17 & 0.000 \\
Message - nutritionally & 92 & 8 & 70.56 & 0.000 \\
$\quad$ beneficial (\%) & & & & \\
Message - healthy (\%) & 94 & 10 & 70.67 & 0.000 \\
Message - tasty (\%) & 92 & 46 & 24.73 & 0.000 \\
Message - fun (\%) & 76 & 84 & 1.00 & NS \\
Message - exciting (\%) & 56 & 76 & 4.46 & 0.03 \\
Message - popular (\%) & 64 & 50 & 1.99 & NS \\
Message - convenient (\%) & 98 & 42 & 37.33 & 0.000
\end{tabular}

NS - not significant.

\section{The advertisement}

As shown in Table 1, there were significant differences in respondents' perceptions of the messages in the advertisement across five of the message variables. Those who saw the adult's version were more likely to perceive that the advertisement suggested the product was nutritionally beneficial ( $92 \%$ vs. $\left.8 \%, \chi^{2}=70.56, P=0.000\right)$, healthy (94\% vs. $10 \%, \chi^{2}=70.67, P<0.000$ ), tasty (92\% vs. $46 \%$, $\left.\chi^{2}=24.73, P=0.000\right)$ and convenient (98\% vs. $42 \%$, $\chi^{2}=37.33, P=0.000$ ). Conversely, those who saw the child's version were more likely to perceive that the advertisement suggested the product was exciting $(76 \%$ vs. $\left.56 \%, \chi^{2}=4.46, P=0.03\right)$.

\section{Advertisement 2: Dairy Whip 'Whipped Cream'}

The product

As shown in Table 2, over $60 \%$ of respondents perceived the product as one they would purchase for themselves to consume, regardless of which advertisement they viewed ( $68 \%$ and $62 \%$, respectively). However, their likelihood of purchasing the product for their children varied substantially depending on the version of the advertisement they saw, with $28 \%$ who saw the adult version stating that they would purchase the product for their child compared with $66 \%$ of those who saw the child version $\left(\chi^{2}=14.49, P<0.000\right)$.

\section{The advertisement}

As shown in Table 2, there were significant differences in respondents' perception of the messages in the advertisements between the two conditions across all seven of the message variables. Those who saw the adult version were more likely to perceive that the advertisement suggested the product was nutritionally beneficial $(26 \%$ vs. $\left.2 \%, \chi^{2}=11.96, P<0.000\right)$ and convenient $(98 \%$ vs. $\left.86 \%, \chi^{2}=4.89, P<0.03\right)$. Conversely, those who saw the child version were more likely to perceive that the advertisement suggested the product was healthy $(74 \%$
Table 2 Dairy Whip 'Whipped Cream'

\begin{tabular}{lccrc}
\hline & $\begin{array}{c}\text { Adult } \\
\text { version }\end{array}$ & $\begin{array}{c}\text { Child } \\
\text { version }\end{array}$ & \multicolumn{1}{c}{$\chi^{2}$} & $P$ \\
\hline Purchase for self (\%) & 68 & 62 & 0.40 & NS \\
Purchase for child (\%) & 28 & 66 & 14.49 & 0.000 \\
Think it's healthy (\%) & 12 & 4 & 2.17 & NS \\
Message - nutritionally & 26 & 2 & 11.96 & 0.000 \\
$\quad$ beneficial (\%) & & & & \\
Message - healthy (\%) & 30 & 74 & 14.58 & 0.000 \\
Message - tasty (\%) & 74 & 90 & 4.34 & 0.03 \\
Message - fun (\%) & 22 & 94 & 55.73 & 0.000 \\
Message - exciting (\%) & 12 & 76 & 44.66 & 0.000 \\
Message - popular (\%) & 10 & 38 & 10.75 & 0.001 \\
Message - convenient (\%) & 98 & 86 & 4.89 & 0.03 \\
\hline
\end{tabular}

NS - not significant.

Table 3 Kellogg's 'Coco Pops'

\begin{tabular}{lccrc}
\hline & $\begin{array}{c}\text { Adult } \\
\text { version }\end{array}$ & $\begin{array}{c}\text { Child } \\
\text { version }\end{array}$ & \multicolumn{1}{c}{$\chi^{2}$} & $P$ \\
\hline Purchase for self (\%) & 34 & 48 & 2.03 & NS \\
Purchase for child (\%) & 82 & 60 & 5.88 & 0.01 \\
Think it's healthy (\%) & 50 & 44 & 0.36 & NS \\
Message - nutritionally & 90 & 24 & 44.43 & 0.000 \\
$\quad$ beneficial (\%) & & & & \\
Message - healthy (\%) & 92 & 36 & 34.03 & 0.000 \\
Message - tasty (\%) & 92 & 70 & 7.86 & 0.005 \\
Message - fun (\%) & 78 & 90 & 2.68 & NS \\
Message - exciting (\%) & 22 & 86 & 41.22 & 0.000 \\
Message - popular (\%) & 26 & 38 & 2.86 & NS \\
Message - convenient (\%) & 80 & 60 & 4.76 & 0.002 \\
\hline
\end{tabular}

NS - not significant.

vs. $\left.30 \%, \quad \chi^{2}=14.58, P<0.000\right)$, tasty $(90 \%$ vs. $74 \%$, $\left.\chi^{2}=4.34, \quad P<0.03\right)$, fun $\left(94 \%\right.$ vs. $22 \%, \quad \chi^{2}=55.73$, $P<0.000)$, exciting (76\% vs. $\left.12 \%, \chi^{2}=44.66, P<0.000\right)$ and would make one popular (38\% vs. $10 \%, \chi^{2}=10.75$, $P<0.001)$.

\section{Advertisement 3: Kellogg's 'Coco Pops'}

The product

As shown in Table 3, a greater proportion of respondents who saw the adult version perceived the product as one they would purchase for their children (82\% vs. 60\%, $\left.\chi^{2}=5.88, P<0.01\right)$.

\section{The advertisement}

As shown in Table 3, there were significant differences in respondents' perceptions of the messages in the advertisements between the two conditions across five of the message variables. A greater proportion of those who saw the adult version perceived that the advertisement suggested the product was nutritionally beneficial (90\% vs. $\left.24 \%, \quad \chi^{2}=44.43, \quad P=0.000\right)$, healthy $(92 \%$ vs. $36 \%$, 
$\left.\chi^{2}=34.03, \quad P=0.000\right)$, tasty $\left(92 \%\right.$ vs. $70 \%, \quad \chi^{2}=7.86$, $P=0.005)$ and convenient ( $80 \%$ vs. $60 \%, \quad \chi^{2}=4.76$, $P=0.002$ ). Conversely, a greater proportion of those who saw the child's version perceived that the advertisement suggested the product was exciting ( $86 \%$ vs. $22 \%$, $\left.\chi^{2}=41.22, P=0.000\right)$.

\section{Advertisement 4: Kellogg's 'LCMs'}

\section{The product}

As shown in Table 4, a significantly greater proportion of those who saw the adult version stated that they would purchase the product for their child to consume (82\% vs. 54\%, $\left.\chi^{2}=9.01, P<0.002\right)$.

\section{The advertisement}

As shown in Table 4, there were significant differences in respondents' perceptions of the messages in the advertisements between the two conditions across six of the message variables. A greater proportion of those who saw the adult version perceived that the advertisement suggested the product was nutritionally beneficial (74\% vs. $\left.14 \%, \quad \chi^{2}=36.53, \quad P=0.000\right)$, healthy $(82 \%$ vs. $26 \%$, $\left.\chi^{2}=31.56, P=0.000\right)$, tasty $\left(90 \%\right.$ vs. $72 \%, \quad \chi^{2}=5.26$, $P=0.02)$, and convenient (98\% vs. $76 \%, \chi^{2}=10.7$, $P=0.001)$. Conversely, a greater proportion of those who saw the child's version perceived that the advertisement suggested the product was exciting ( $84 \%$ vs. $32 \%$, $\left.\chi^{2}=27.75, P=0.000\right)$ and would make one popular $(78 \%$ vs. $\left.56 \%, \chi^{2}=5.47, P<0.02\right)$.

\section{Discussion}

The results of this study suggest that: (1) adults' perceptions of advertised food products and purchase intentions for those products differ according to the version of the advertisement seen; and (2) adults clearly perceive distinctly different messages in advertisements for the same

Table 4 Kellogg's 'LCMs'

\begin{tabular}{lcccc}
\hline & $\begin{array}{c}\text { Adult } \\
\text { version }\end{array}$ & $\begin{array}{c}\text { Child } \\
\text { version }\end{array}$ & $\chi^{2}$ & $P$ \\
\hline Purchase for self (\%) & 16 & 10 & 0.80 & NS \\
Purchase for child (\%) & 82 & 54 & 9.01 & 0.002 \\
Think it's healthy (\%) & 42 & 34 & 0.68 & NS \\
Message - nutritionally & 74 & 14 & 36.53 & 0.000 \\
$\quad$ beneficial (\%) & & & & \\
Message - healthy (\%) & 82 & 26 & 31.56 & 0.000 \\
Message - tasty (\%) & 90 & 72 & 5.26 & 0.02 \\
Message - fun (\%) & 72 & 84 & 2.78 & NS \\
Message - exciting (\%) & 32 & 84 & 27.75 & 0.000 \\
Message - popular (\%) & 56 & 78 & 5.47 & 0.02 \\
Message - convenient (\%) & 98 & 76 & 10.70 & 0.001 \\
\hline
\end{tabular}

NS - not significant. products which are targeting parents vs. those targeting children.

With regard to perceptions of food products and associated purchase intentions, the most interesting aspect of the results is the differences in purchase intentions in response to the two ad types, with parents significantly more likely to purchase foods after seeing the adult's version of the ads (or, conversely, less likely to purchase them after seeing the children's versions) for three of the four food products (Go-Gurts, Coco Pops and LCMs). Adults were also more likely to perceive these foods as healthy if they read the adult version of the advertisement.

The results for Dairy Whip differ from the other three products - this may suggest that if parents see advertisements targeted at children for products that they do not traditionally associate with children, they may be more likely to purchase it for their child.* In contrast to the other types of advertisements and products, it would be in the interest of marketers to have parents see these children's advertisements.

With regard to the perceived messages, there was a clear pattern of the adult-targeted advertisements portraying the foods as nutritious, healthy, tasty and convenient (except for Dairy Whip); and the child-targeted advertisements portraying them as fun, exciting products that would make the consumer popular. These different messages are consistent with what one might expect to be the food values of the two groups - adults and children with adults (parents) valuing foods for children that are nutritionally beneficial, healthy, tasty and convenient; and children valuing fun, exciting foods that may make them popular. Advertisers are obviously successfully tapping in to these values with messages that selectively appeal to these values, and in the long run may also be reinforcing these values regarding what is important in food. The messages in the children's/adult's advertisements are not necessarily incompatible however - in the same way that you may try to make vegetables 'fun' for children by making faces with sprouts for hair, etc.

However, these results do suggest that it is in the marketers' interest to target children in a more 'private' way (i.e. via media which parents are unlikely to be exposed to) and magazines seem to provide a way to do this that television cannot provide. This is particularly so as parents seem unaware of the amount of advertising in children's magazines. It is reasonable to assume that parents are more likely to see and hear advertisements on television, even those aired during children's programming, than those in children's magazines. It is concerning that parents have differing perceptions of products when

\footnotetext{
* As pointed out by an anonymous reviewer, the fact that this is an 'indulgence' product - targeted at, and consumed by, both adults and children - could explain the difference in results between this and the other products.
} 
they are 'kept away' from images and messages that their children are exposed to. The importance of this is underscored by a recent study which found that the presence of children in a household is associated with increased consumption of high-fat and other unhealthy snack foods among adults ${ }^{33}$, which suggests that advertising that effectively targets children has the potential to affect the diet of all family members.

These results illustrate just how much perceptions of food products are determined by advertising messages. It is concerning that if advertising messages are not nutritionally accurate, or promote a biased account of nutritional benefit and 'healthiness', children may be exposed to food that parents would not choose for their children if they had the full information given in an unbiased way.

\section{Limitations}

The use of a between-subjects design means that we cannot directly compare the effect of different advertisement types on an individual's purchase intentions or interpretations of the advertisement's message. However the alternative, a within-subjects design, would have had considerable potential for confounding as respondents would have been interpreting the second advertisement exposed in the context of the information in the first advertisement; and would have been inconsistent with the real-life situation in which individuals are likely to be exposed to only one advertisement for a given product.

Due to the nature of the study - an intercept survey conducted in a central business district - which necessitated keeping the questionnaire length as short as possible, there were a number of questions we did not ask. For example, we did not ask about respondents' potential mediators such as pre-existing brand awareness or brand attitudes; prior exposure to the advertisements; or purchase habits in relation to the advertised brands or product types. Further, as we did not have a control group and did not measure pre-exposure effects, it is likely that some of the responses reflected these pre-existing attitudes (e.g. Coco Pops had received negative publicity about its advertising campaigns); although there is no reason to suppose that these would have a differential effect across the two conditions.

Finally, the use of a convenience sample and the fact that the study was conducted in a shopping centre in a regional Australian city mean that the results may not be generalisable to people in different regions or countries; although collecting the data at the region's major shopping centre increases the likelihood that the sample was representative of grocery shoppers in this region. We did not include being a parent as an inclusion criterion for participation in the study, which could have been a limitation - particularly as one of the questions directly asked respondents about purchase intentions for their children or, for those who did not have children, whether they would if they had children. Thus, analyses were conducted to determine whether the responses from parents differed from non-parents. Of the 80 items (i.e. 10 questions for each of eight ads), there were only five that differed between parents and non-parents (in all cases, the child version). Two of these related to perceptions that the advertisement implied consuming the advertised food would make one popular (Go-Gurts: $\chi^{2}=6.44$, $P=0.01$; Coco Pops: $\left.\chi^{2}=9.91, P=0.002\right)$, two to perceptions of Go-Gurts (healthy: $\chi^{2}=5.99, P=0.03$; nutritionally beneficial: $\left.\chi^{2}=6.20, \quad P=0.04\right)$ and one to willingness to purchase Coco Pops for a child $\left(\chi^{2}=5.99\right.$, $P=0.03)$.

\section{Future research}

Our results do not actually indicate whether seeing a children's ad in the absence of viewing an adult ad would reduce purchase intention compared with seeing no advertising. Future research could ask 'would this ad make you more likely to purchase the product' rather than just 'how likely are you to purchase the product'. Future research could also include showing both adultand child-targeted advertisements to the same respondents, and comparing their responses with those who only see the adult ad. We also note that adults may be so accustomed to advertisers targeting their 'healthy' food values, and making use of anything that could be called healthy about a product, that if they see an advertisement which does not do this they may presume that it is extremely unhealthy, and hence reduce purchase intention. Alternatively, it is possible that the reduced purchase intention in response to child-targeted advertisements is related to adults' philosophical objections to advertisers targeting children; or that advertisements which are visually designed to appeal to children are simply unappealing to adults. These potential explanations for the effects found could be explored in future research.

\section{Conclusion}

In conclusion, it is clear that the messages conveyed to children about specific foods are quite different to the messages conveyed to adults, and importantly parents, about the same foods. This has important implications for those concerned with the monitoring and regulation of food advertising. Previous research has shown that food advertising can be effective in persuading parents that unhealthy food products are actually good for their children $^{34}$, generally by focusing on one 'healthy' ingredient (such as calcium), and there has been widespread public condemnation (led by the Parents Jury) of such deceptive advertising practices and calls for a ban on junk food advertising to children ${ }^{35}$. However, this strategy of attempting to deceive consumers into perceiving a food 
as healthy, rather than actually modifying its nutritional content, is not exclusive to child-targeted foods - in the words of an Advertising Federation of Australia executive, '...the trend is to tie products to healthful pursuits. Even in ads for burgers or pizza, you increasingly see people playing sports, working out or playing at the beach. They're working up an appetite - and burning up calories $^{36}$. There is a clear need to develop appropriate strategies to increase the awareness of parents and, equally importantly, regulators and other stakeholders of the contradictory messages being conveyed; and to provide young people and their caregivers with the necessary media literacy skills to counter such misleading messages.

These findings also have important implications for those directly involved in developing social marketing campaigns aimed at improving the nutritional intake of children and young people. Social marketers could learn much from commercial marketers about the development of messages that are appealing to the target audience and the selection of communication channels that reach these audiences. However, an important caveat on this recommendation is that, in developing messages for the different target audiences, we do not fall into the trap of doing what we are suggesting commercial marketers should not do but ensure that all messages are honest, accurate and conveyed in an ethical fashion.

\section{References}

1 Story M, French S. Food advertising and marketing directed at children and adolescents in the US. International Journal of Behavioural Nutrition and Physical Activity 2004; 1: 3.

2 Kumanyika S, Jeffery R, Morabia A, Ritenbaugh C, Antipatis $\mathrm{V}$. Obesity prevention: the case for action. International Journal of Obesity and Related Metabolic Disorders 2002; 26: 425-36.

3 Booth ML, Wake M, Armstrong T, Chey T, Hesketh K, Mathur S. The epidemiology of overweight and obesity among Australian children and adolescents 1995-1997. Australian and New Zealand Journal of Public Health 2001; 25: 162-9.

4 O'Dea J. Prevention of child obesity: first, do no harm. Health Education Research 2005; 20: 259-65.

5 Variyam J, Blaylock J, Lin B, Ralston K, Smallwood D. Mother's nutrition knowledge and children's dietary intakes. American Journal of Agricultural Economics 1999; 81: 373-84.

6 Hampl JS, Taylor CA, Johnston CS. Intakes of vitamin C, vegetables and fruits: which schoolchildren are at risk? Journal of American College of Nutrition 1999; 18: 582-90.

7 Skinner JD, Betty RC, Houck KS, Bounds W, Morris M, Cox DR, et al. Longitudinal study of nutrient and food intakes of white preschool children aged 24 to 60 months. Journal of the American Dietetic Association 1999; 99 : 1514-21.

8 Butriss J. Nutrition in General Practice, 1st ed. London: Royal College of General Practitioners, 1995.

9 Neumark-Sztainer D, Story M, Perry C, Casey MA. Factors influencing food choices of adolescents: findings from focus-group discussions with adolescents. Journal of the American Dietetic Association 1999; 99: 929-37.

10 Nestle M, Wing R, DiSogra L, Drewnowski A, Arbor A, Middleton S, et al. Behavioral and social influences on food choices. Nutrition Reviews 1998; 56: S50-74.

11 Booth S, Mayer J, Sallis J, Ritenbaugh C. Environmental and societal factors affect food choice and physical activity: rationale, influences, and leverage points. Nutrition Reviews 2001; 59: S21-39.

12 Devine C, Connors M, Bisogni C, Sobal J. Life-course influences on fruit and vegetables trajectories: qualitative analysis of food choices. Journal of Nutrition Education 1998; 30: 361-70.

13 Morton H. Television food advertising: a challenge for the new public health in Australia. Community Health Studies 1990; 14: 153-61.

14 Story M, Faulkner P. The prime time diet: a content analysis of eating behaviour and food messages in television program content and commercials. American Journal of Public Health 1990; 80: 738-40.

15 Taras HL, Gage M. Advertised foods on children's television. Archives of Pediatrics \& Adolescent Medicine 1995; 149: 649-52.

16 Australian Division of General Practice. What are we feeding our children? A junk food advertising audit [online], February 2003. Available at http://www.adgp.com.au/ client_images/1743.pdf. Accessed 10 December 2006.

17 Wilson N, Quigley R, Mansoor O. Food ads on TV: a health hazard for children? Australian and New Zealand Journal of Public Health 1999; 23: 647-50.

18 Campbell K, Crawford D. Family food environments as determinants of preschool-aged children's eating behaviours: implications for obesity prevention policy. A review. Australian Journal of Nutrition and Dietetics 2001; 58 : $19-25$.

19 Hupkens CLH, Knibbe RA, Otterloo AHV, Drop MJ. Class differences in the food rules mothers impose on their children: a cross-national study. Social Science \& Medicine 1998; 47: 1331-9.

20 Fisher J, Birch LL. Restricting access to food and children's eating. Appetite 1999; 32: 405-19.

21 Birch LL. Development of food preferences. Annual Review of Nutrition 1999; 19: 41-62.

22 Casey R, Rozin P. Changing children's food preferences: parents' opinions. Appetite 1989; 12: 171-82.

23 Stanek K, Abbott D, Cramer S. Diet quality and the eating environment of preschool children. Journal of the American Dietetic Association 1990; 90: 1582-4.

24 Vereecken CA, Keukelier E, Maes L. Influence of mother's educational level on food parenting practices and food habits of young children. Appetite 2004; 43: 93-103.

25 Contento IR, Basch C, Shea S, Gutin B, Zybert P, Michela JL, et al. Relationship of mothers' food choice criteria to food intake of preschool children: identification of family subgroups. Health Education Quarterly 1993; 20: 243-59.

26 Wardle J. Parental influences on children's diets. Proceedings of the Nutrition Society 1995; 54: 747-58.

27 Donkin AJ, Tilston CH, Neale RJ, Gregson K. Children's food preferences: television advertising versus nutritional advice. British Food Journal 1992; 94: 6-9.

28 Borzekowski DLG, Robinson TN. The 30 second effect: an experiment revealing the impact of television commercials on food preferences of preschoolers. Journal of the American Dietetic Association 2001; 101: 42-6.

29 McNeal N. Children as Consumers: Insights and Implications. New York: Lexington Books, 1987.

30 Owen S. Food choice: how to assess attitudes of preadolescent children. British Food Journal 1997; 99: 148-53. 
31 Hoang C, Jones SC, Thornton J. Consumer confusion: parents' nutritional perceptions in food advertisements. In: Celebration of Ebrenberg and Bass, Australia and New Zealand Marketing Academy Conference Proceedings. Adelaide: University of South Australia, 2003; 1984-9. Also available at http://smib.vuw.ac.nz:8081/Www/ ANZMAC2003/papers/POL16_hoangc.pdf. Accessed 11 January 2007.

32 Shimp T. Advertising, Promotion and Supplemental Aspects of Integrated Marketing Communications, 4th ed. Fort Worth, TX: Harcourt Brace College Publishers, 1997.

33 Laroche HH, Hofer TP, Davis MM. Adult fat intake associated with the presence of children in households: findings from NHANES III. Journal of the American Board of Family Medicine 2007; 20: 9-15.

34 Hoang C, Jones SC, Thornton J. The influence of magazine advertising on parents' nutrition ratings of food products for children. In: Accountabilities and Responsibilities in Marketing: Proceedings of the 2004 ANZMAC Conference, Wellington, New Zealand, 2004 [online]. Available at http:// smib.vuw.ac.nz:8081/WWW/ANZMAC2004/CDsite/papers/ Hoang1.PDF. Accessed 8 December 2006.

35 Bunce J. Parents want junk food ads banned. Daily Telegraph, 16 May 2007.

36 Pritchard C. Food marketers feel the heat down under. Marketing Magazine 2003; 10: 7. 